\title{
A Model and Complexity Analysis of the Relationship Based on Organizational Justice and Embeddedness Theories
}

\author{
Xin Su $\left(\mathbb{D},{ }^{1,2}\right.$ Hui Zhang, ${ }^{1}$ and Shubing Guo ${ }^{3}{ }^{3}$ \\ ${ }^{1}$ Shandong University of Finance and Economics, School of Business Administration, Jinan 250014, China \\ ${ }^{2}$ Research Center of Government Performance Evaluation of Shandong University of Finance and Economics, \\ Jinan 250002, China \\ ${ }^{3}$ College of Management and Economics, Tianjin University, Tianjin 300072, China \\ Correspondence should be addressed to Xin Su; sdcjsx2016@126.com and Shubing Guo; sbguo20160831@126.com
}

Received 20 September 2019; Revised 16 March 2020; Accepted 2 April 2020; Published 25 April 2020

Academic Editor: Eulalia Martínez

Copyright (C) 2020 Xin Su et al. This is an open access article distributed under the Creative Commons Attribution License, which permits unrestricted use, distribution, and reproduction in any medium, provided the original work is properly cited.

\begin{abstract}
In capable person governing agricultural cooperatives, the internal governance is essential for cooperatives to achieve sustainable development. As an important mechanism of cooperative internal governance, relational governance is the focus of the current research in the field of cooperative internal governance. Based on the theory of organizational justice, relational embeddedness theory, and relational governance theory, this paper constructs the relationship between interactive justice, relational embeddedness, and governance performance based on fuzzy cognitive map and discusses the influence mechanism of interactive justice on relational governance performance. Taking 245 members of 18 agricultural cooperatives as samples, this paper makes an empirical test by using the machine learning method. Through the analysis of the data, we find that interactive justice has a significant positive impact on the governance performance. Relational embeddedness also has a significant positive impact on the governance performance. And relational embeddedness plays an intermediary role in the positive impact of interactive justice on governance performance. To some extent, the research results broaden the relationship between interactive justice and relational governance performance and provide useful reference for cooperatives to strengthen internal governance and achieve sustainable growth.
\end{abstract}

\section{Introduction}

The relationship models have very important applications in management. Relationship models are generally based on some theory to explain the causal relationship between variables. There are already many models trying to abstract various relationships and build models. Different models are extremely dependent on different research questions. For example, Feng and Li explored the mechanism of interorganizational dependence on supply chain performance by establishing a relationship model among interorganizational dependence, relational governance mechanism, and supply chain performance based on the views of interorganizational dependence and relational governance [1]. Yu et al. constructed the relationship model between professional knowledge search, management innovation, cognitive evaluation, and enterprise performance by referring to the knowledge search theory and cognitive evaluation theory, in order to investigate the adoption process of dual management innovation and the impact of its implementation on enterprise performance [2]. In this paper, we consider the relationship among members of agricultural cooperatives and establish an abstract model of interactive justice, relational embeddedness, and governance performance.

Since the new century, the central document advocated the development of new business entities and the construction of a variety of new farmer cooperative organizations in order to alleviate the inhibitory effect of the "three rural issues" in the process of agricultural industrialization in China. In addition, weak and potential factors such as high risk of agricultural production improve farmers' organization level and facilitate the emergence of farmer cooperatives [3]. Agricultural cooperatives such as new rural cooperative management organization can make the 
dispersed farmers together effectively and enhance its competitive position in the market, reduce transaction costs, and improve the income level of farmers [4]. By the end of 2015, there have been about 153 registered cooperatives and 10 million members in China.

Based on the different types of governing person, four modes of Chinese agricultural cooperatives are as follows: rural capable person leading, government departments, leading enterprises, and farmers' self-organization. Among them, capable person leading type is most typical in China, and it is a kind of double principal-agent relationship. The capable person and members depend on each other because they are interest community. On the one hand, capable people accept members' requirements to manage agricultural cooperatives and ultimately improve the members' income level; on the other hand, the members pay agricultural products of high-quality standards according to the commission of capable person in order to enter the market successfully. However, the external institutional environment of China's agricultural cooperatives governance is not perfect, and the membership heterogeneity is more obvious. Therefore, how to solve problems of agricultural cooperatives internal governance is very important for local government and management personnel of agricultural cooperatives. Relational governance refers to the informal culture and system that affect the relationship subject, which is embodied in a mechanism to stimulate self-management, such as information sharing, trust, and cooperation [5]. In addition, relational governance to some extent reflects that the relationship is restricted by common norms and social mechanisms. It enforces obligations and expectations through social processes that promote relational norms and rely on mutual adjustment and joint action [6]. So the relational governance is a necessary component of firm through which both subjects behave with the aim of achieving the joint objectives [7]. Chinese rural society forms layers of social network according to their different affinities, and the characteristics of different sequence are significant. In view of the fact that China's agricultural cooperatives form on the basis of geographical relations, the relationship between capable person and members is made up of a variety of social relations. Thus, the capable person divides members into core members (technical experts) and ordinary ones (small farmers) based on his social communication experience and difference sequence of "acquaintance society," and the heterogeneity of core members and ordinary ones with different capital endowments and production scale may easily lead to the emergence of internal unfair interaction phenomena and inconsistent benefits allocation problems. Capable person and core members can often form a community of interests. However, it may fall into the low level state of cooperation when capable person chooses the ordinary ones [8], and it will affect the enthusiasm and participation of ordinary members into agricultural cooperatives. In addition, it may cause the lack of intrinsic motivation and is not good for the long-term stability of cooperation between the two sides.

The implementation of the "farmer cooperatives law" in 2007 has standardized the internal governance behavior of
Chinese rural cooperatives to a certain extent and ensured the farmers' power to participate in the governance of agricultural cooperatives. However, the local government after performance tends to increase the supports of functional cooperatives, which lead to the mismatch of preferential resources [9]. A series of problems appear subsequently in agricultural cooperatives, such as agricultural cooperatives uneven in quality, "generalization" and "alienation" phenomenon is serious, and the appearance of "shell cooperatives" and "false cooperatives." In addition, at the microlevel, the governance of capable person leading cooperatives emphasize relational governance and its "coreperiphery" structure [10] and "large farmers merges small farmers" logical characteristics are unfavorable for the realization of ordinary members' governance power; that is to say, the participation aspiration of members is not strong.

To solve the problems mentioned above, based on the principal-agent theory, social capital theory, and incomplete contract theory, some scholars consider that the key problem of agricultural cooperatives' internal governance lie in some aspects, such as the incomplete property rights and governance structure and contract execution; supervision is not in place, and the decision is not scientific and so on. They put forward a series of measures. For example, through effective communication, mutual compensation, and reasonable arrangement of the equity, agricultural cooperatives could solve problems such as the trust and coordination problems, internal control by a few people, and the distribution of benefits or other issues between heterogeneity members [11]. Some scholars believe that the structure of governance under the extensive participation of members is the key to improve the governance performance of agricultural cooperatives. Based on the BP neural network, some scholars construct a comprehensive performance evaluation model [12, 13], in order to test the relationship between breakthrough innovation factors and innovation performance [14]. To sum up, the internal governance of the agricultural cooperatives is still the core issue that the domestic and foreign scholars pay close attention to, and there is more experience about the participation, satisfaction, and commitment of the members [8]. The internal governance of agricultural cooperatives mainly exists in two different forms, that is to say, interest orientation and fairness orientation [15]. The fairness orientation is that capable person shows his interactive justice with different members in the process of agricultural cooperatives governance.

Although scholars at home and abroad have explored the influencing factors of the governance performance of the capable person governing agricultural cooperatives based on different theoretical perspectives, or have taken relational governance as an independent variable to study the mechanism of relational governance on knowledge flow [16], social sustainability [6], social performance, and innovation performance [7], the relationship between the internal members interactive justice perception and relational governance performance is rarely mentioned. In addition, the members interactive justice perception will affect their embedded interpersonal relationships, such as the intimacy degree among members in the network. A 
highly intimate relationship forms a mechanism of mutual trust, efficient information sharing, and transmission and collaborative problem-solving among members. The higher the intimacy degree is, the higher the frequency of sharing information and exchanging views among members is, and the greater the impact of relational embeddedness on subject behaviors and performance is. Therefore, relational embeddedness may play an intermediary role in the impact of interactive justice on relational governance performance. In view of this, this paper mainly studies the influence mechanism of interactive justice on relational governance performance based on the theories of organizational justice, relational embeddedness, and relational governance. Through the in-depth discussion of this issue, we can provide references for the rural cooperatives to get out of the dilemma of internal collective action.

\section{Theories and Hypotheses}

2.1. The Influence of Interactive Justice on the Relational Governance Performance of Rural Cooperative. The equity theory holds that the perception of organizational justice is individual or groups' subjective feelings about relevant organizations' action on them. Organizational justice initially was divided into two dimensions, that is to say, procedural justice and distributive justice. Then, Bies and Moag began to pay attention to the effects of interpersonal interaction on the perception of organizational justice when organizational program executes and regarded that interactive justice is independent of procedural justice and distributive justice, and it was represented as individual sensitivity of interpersonal communication and interaction [17] or the perceived quality of interpersonal treatment. Since then, interactive justice has been further subdivided into two aspects: interpersonal justice and informational justice, which, respectively, represent communication, information transmission, and attitude transmission $[18,19]$. Interpersonal justice mainly refers to whether members can acquire particular treatment from superior organization, such as respect, courtesy, and trust, and its role is changing the individual reaction on organizational decision. However, the informational fairness shows whether the organization conveys effective information to individuals or gives the reasonable explanation of decision result, which can enable the individuals to better understand the allocation result by changing the individual response to organizational procedures [20]. In view of the strong fairness preference of the members, the more equitable the distributive benefits of cooperatives, the stronger the will of members joining the agricultural cooperatives.

Based on the equity theory, some scholars think that interactive fairness refers to the interpersonal treatment of organizational members in the process of implementation of organizational procedures. Interactive fairness usually occurs between leaders and members [21]. In addition, some scholars have proposed that interactive justice can affect organizational outcome variables, such as organizational citizenship behavior and organizational performance [22]. In view of the main problem of this paper is the mechanism of the interactive justice between capable people and members on the cooperatives relational governance performance, and the justice theory provides a substantial theoretical basis for this.

The assumption of limited rationality and incomplete information between each subject is preconditions of relational governance theory. The relational governance theory acts as an important complement to formal contract governance, and it is mainly composed of open communication, information sharing, trust, and cooperation relationship. However, internal governance performance of agricultural cooperatives is measured by "the increase of income," "satisfaction" of members, and "internal harmony." The "diversity pattern" view proposed by Fei Xiaotong is the representative of domestic scholars' research on relationship, and it regards that interpersonal interaction of individuals conducts themselves as the center and divides others into different layers based on the closeness, which can reflect differentiated interpersonal treatment and elastic pattern boundaries, and it represents the fair perception of subject to a certain extent.

In the management process of capable person leading cooperatives, core members and ordinary ones can obtain differentiated preferential distribution of interests because of their different resource endowments. Thus, their fair perception is also different. First of all, in terms of interpersonal fairness, the closer the relationship between members and capable person is, the more frequently they exchange and communicate with each other based on mutual respect [8]. As a result, the conflict of interest between them is more and more less, and the relational governance performance is higher with the decline of coordination cost. Secondly, if the members think they are treated equally compared to the others, their enthusiasm of participating in agricultural cooperatives management, the efficiency of preventing or solving agricultural problems, and governance performance are much higher. In terms of informational fairness, if one member can get all the producing or planting information like the other members from capable person or agricultural cooperatives, then he forms strong dependence on capable or agricultural cooperatives. As a result, he will actively participate in agricultural cooperatives to reflect their own value and obtain more valuable information [23], which is conducive to the governance performance of agricultural cooperatives to a certain extent. In addition, in process of agricultural cooperatives making decision results such as internal distribution of benefit or the organization of production open, if each member can obtain explanation or replies on the decision results, his willingness of participating in agricultural cooperatives may be higher and he will not take opportunistic behavior [20], and the relational governance performance is higher. On the contrary, if one member cannot obtain reasonable replies or explanation, he is more possible to breach the contract or take action of "free rider," which makes the problems of governance in agricultural cooperatives more serious.

In summary, the interaction between members and capable person takes effect by two ways. On the one hand, interpersonal fairness perception can make the members' 
social needs met and feel be respected, which is incentive to actively participate in governing agricultural cooperatives and improves the governance performance through communication and coordination of interest. On the other hand, informational fairness perception can make all the members obtain common information or rationalized explanation on decision-making, which may urge the internal relationships in agricultural cooperatives more harmonious. Therefore, based on the above theoretical deduction, this paper proposes hypothesis 1 :

$\mathrm{H} 1$ : interactive justice has a positive impact on the governance performance of rural cooperatives

H1a: interpersonal justice has a positive impact on the governance performance of rural cooperatives

H1b: informational justice has a positive impact on the governance performance of rural cooperatives

2.2. The Influence of Relationship Embeddedness on the Relational Governance Performance of Rural Cooperative. The influence of relational embeddedness on the governance performance of rural cooperatives takes effect through three dimensions, namely, trust, information sharing, and common solution. The process is as follows.

For one thing, trust, as an informal norm, can promote the sharing of knowledge among partners, and thereby, it inhibits the emergence of "free rider" behavior. First of all, the frequent communication and interaction between the members and capable person is beneficial to discover governance problems or agricultural product quality problems in time, which can be prevented or solved by taking effective measures quickly, and it makes the internal relationships in agricultural cooperatives more harmonious, reduces the transaction cost and the cost of supervision, and improves governance performance. Secondly, the capable person and members keep their promises to promote the effective implementation of the order contract, which can inhibit the opportunism behavior, alleviate the interest conflicts between different subjects, and improve the governance performance of agricultural cooperatives. In addition, the increase in trust level makes members believe that the resources or information they obtained from capable person is valuable for them; thus, they will actively cooperate with capable person to manage agricultural cooperatives based on their dependence on the capable person, and they support his decision results. The relationship between the members and capable person is more harmonious, and the governance performance is higher.

For another, the exchange of information between capable person and members can realize the sharing of information, and the information content mainly includes both shared goals, values, market price of agricultural products, quality and safety information, and market demand [24]. First of all, through carrying out collective internal meeting actively, the capable person shares information effectively to the members or public, which can help members find problems in the process of agricultural production, and it is propitious to capable person to find out nonstandard behaviors or decisions, reduce losses or costs, and provide new opportunities of collaboratively governing agricultural cooperatives for members and the capable person. Secondly, the sharing of future development plans among members and the capable person will be good for forming common interests and goals and lay the foundation of improving governance performance and coordinate behaviors based on the same target specification [25]. In addition, the increase in information sharing level can make agricultural cooperatives get more heterogeneous resources or information, and the members will obtain more information about agricultural planting technology guidance, market dynamics, and quality evaluation standards of agricultural products, which create good conditions for members to improve agricultural products planting efficiency and increase their income level. On the basis of this, the enthusiasm of the members participating in both agricultural cooperatives and governance performance is increasing. And the capable person can get real dose of pesticide and fertilizer used by members in the process of agricultural production, which provides information for the assessment of the quality level of agricultural products, and so that agricultural products on different levels flow into different markets, which can avoid the market risk and improve the performance of agricultural cooperatives.

In addition, the mutual help between the capable person and members is conducive to enhance the enthusiasm of the members participating in the internal governance of agricultural cooperatives, restraining members "free rider" behavior, breaking the dilemma of collective actions in agricultural cooperatives, and ultimately improving the governance performance. The capable person and members make joint efforts to undertake the responsibility of governance and sustainable development of the rural cooperatives, which can coordinate their behaviors, reduce the interest conflicts and transaction costs, and raise the profitability of the agricultural cooperatives. In the process of members' participating in the discussion of internal governance, the members and capable person interact and communicate with each other, which is essential to reduce friction and improve the governance performance of the agricultural cooperatives.

Thus, relational embeddedness can get out of the dilemma of collective action effectively through three dimensions, namely, trust, information, and joint problem solving, and then it improves the governance performance. However, some scholars believe that the positive impact of relational embeddedness is not always on the governance performance, and there may be an inverted " $U$ " relationship between them, so the researches on the effects of relational embeddedness on performance result in a kind of "embeddedness paradox." The reason is mainly manifested in the following aspects. For one thing, the members and capable person believing in each other excessively will make themselves have a cognitive bias and take limited rational behavior, which leads to the increase in cognitive costs and relationships maintaining costs. For another, the excessive trust, information sharing, and joint solving problems may cause the members and capable person overly depend on 
each other [26,27] and easily make internal resources to be homogeneous, which is not conducive to innovative performance. In addition, the circle with closed groups formed by strong ties brings some benefits, but it inhibits the influx of other new members or resources, which is bad for increasing the innovative performance. In conclusion, the moderate level of relational embeddedness has a positive impact on the governance performance, while the exorbitant level of relational embeddedness has a negative impact on the governance performance.

Therefore, based on the above literature review and theoretical analysis, this paper puts forward the hypothesis 2 :

$\mathrm{H} 2$ : there is an inverted " $\mathrm{U}$ " relationship between the relationship embeddedness and the governance performance

H2a: there is an inverted " $U$ " relationship between trust and governance performance

$\mathrm{H} 2 \mathrm{~b}$ : there is an inverted " $U$ " relationship between information sharing and governance performance

$\mathrm{H} 2 \mathrm{c}$ : there is an inverted " $U$ " relationship between joint solving problems and governance performance

2.3. The Mediating Effect of Relational Embeddedness. The relational embeddedness theory, as an extension of the social capital theory, is originally proposed by Granovetter, and it mainly describes the closeness and quality of the relationship between the individuals and organizations in social network. The individuals or organizations can obtain valuable information through the bridging effect of structural holes.

Some scholars divide the relational embeddedness into different dimensions based on different perspectives. Among them, Wang regards that relational embeddedness consists of three aspects: relational strength, relational stability, and relational quality, based on the frequency of the interpersonal interaction, trust, and reciprocity exchange in the relational network. The relational strength can be further divided into strong ties and weak ties [28, 29]. Strong ties focus on the frequent interpersonal information communication and strong level of trust [30], and weak ties emphasize how to effectively obtain new information [31]. In addition, some scholars suggest that relational embeddedness mainly includes three dimensions based on empirical data, namely, trust, information sharing, and joint solving problems $[30,32]$. This paper also uses this classification method to measure the variable of relational embeddedness. The trust refers to one party in the network which believes that another party will not use the weakness of the partnership to detract his interests in social psychology course [33]. However, the trust in this paper reflects that the members or capable person will consider the interests of the other party in advance when they make decisions or take some action in the process of the internal governance, which will urge both of them to establish the confidence and expectation of collaborative relationships. The information sharing refers to the process of active exchange of information between the capable person and members, which is conducive to the development of the agricultural cooperatives, and the exchange process is not bound by the established agreement [34]. The joint solving problems refer to the members and capable person can provide mutual help and encouragement for each other in the future in order to solve the problems or difficulties existing in relational governance, complete a task or transaction, and keep sustainable and stable relations between the two sides.

The interactive fairness is related to interpersonal relationships embedded by individuals, and it emphasizes on the degree of fairness of interpersonal treatment they perceive in the process of executing decision or solving the internal problems. For internal governance of capable person leading cooperatives, the interactive justice manifests concretely that the capable person treats different members divided in interpersonal closeness by different ways, which can make the members come into the perception of interpersonal fairness and informational fairness. The members' perception of interactive fairness will have a certain impact on its embedded interpersonal relationships, which embodies in the following two aspects.

On the one hand, the more frequently the members and capable person communicate and exchange out of respect, the more they are likely to understand each other, and the mutual trust level will be higher with increasing closeness between them, which can further strengthen cooperation between the two sides, avoid the friction problems because of distrust, and finally improve the governance performance of agricultural cooperatives $[35,36]$; the improvement of communication frequency can increase the level of information sharing to a certain extent, which may reduce the risk caused by asymmetry and incomplete information, and finally, it is beneficial to solve the problems of internal governance $[8,37,38]$; the more they are likely to discuss a problem together, such as the problem of the production and marketing of agricultural products, the more they are likely to solve the problem or improve the efficiency of solving problem through effective consultation ultimately [39-43].

On the other hand, the members can improve the disadvantage of their incomplete information if they have access to effective information, which will help them improve the efficiency of agricultural production and their income levels. The improvement of members' income can make the members depend on the capable person or agricultural cooperatives even more. With the increase in interest distribution the members can obtain, the members are more willing to share information, work together to solve problems, and improve the internal performance of agricultural cooperatives. In addition, it is beneficial to make the members feel they have a certain status in the agricultural cooperatives, if the decision results of benefits distribution can be explained reasonably, and their demand of social respect has been met. As a result, the members tend to believe that the capable person or agricultural cooperatives can be believed in and worth relying on them, and then the members create a sense of trust on them and share responsibilities of the development of agricultural cooperatives. The members are willing to share the heterogeneous information because of the incentive of being respected, which can weaken the problem of internal information 
asymmetry and provide a new opportunity for the development of agricultural cooperatives. If the members' internal status can be recognized, they will actively make contribution to the future of agricultural cooperatives to a certain extent and help the capable person overcome the problems and difficulties in the agricultural cooperatives [41-47].

In conclusion, the interaction between the members and capable person through interpersonal fairness and informational fairness can strengthen the degree of exchange of information, trust, and joint solving problems, which may be good for improving their relational embeddedness in the whole network. Therefore, based on the above analysis, this paper puts forward the hypothesis 3 :

H3: relational embeddedness has mediating effect on the relation between interactive justice and governance performance.

H3a: relational embeddedness has mediating effect on the relation between interpersonal justice and governance performance.

H3b: relational embeddedness has mediating effect on the relation between informational justice and governance performance. The model of relations between interactive justice, relational embeddedness, and governance performance is shown in Figure 1.

\section{Research Design}

\subsection{Data Collection and Variable Measurement}

3.1.1. Data Collection. As a new type of farmer cooperative management organization, Chinese rural cooperative is a special form of enterprise. The cooperatives run by the capable person are typical representatives of farmers' cooperative organizations, and they represent a dual principalagent relationship, in which the capable person and the members are interdependent as a community of interests. In view of the large gap between members' social status and the serious problem of cooperative relational governance in the capable person leading cooperatives, this paper takes the capable person leading cooperatives as the research object to explore the impact mechanism of interactive justice on cooperative relational governance performance [45-51].

Based on the clear labor division, the members of the provincial research team went to several counties in Shandong Province to carry out field research from July to September 2019, such as Linqu, Qingzhou, and Zibo. This paper takes 18 agricultural cooperatives of Shandong Province in China as samples which plant vegetables or seedlings, and this paper sends the questionnaire to members. Although the sample data are filled in by members, the items in the questionnaire reflect the members interactive justice' perception, relational embeddedness, and cooperative relational governance performance. The content of the questionnaire concerns the basic personal characteristics of the members, such as gender, age, education, income and their justice perception, relational embeddedness, and governance performance. A total of 320 questionnaires were

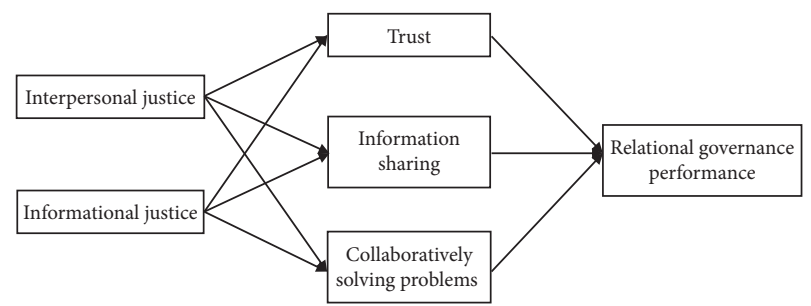

FIgURE 1: Model of relations between interactive justice, relational embeddedness, and governance performance.

issued, and 245 valid questionnaires were recovered with an effective rate of $76.56 \%$. In order to further test the questionnaire's response bias, the $T$ test was carried out on the reclaimed and mot reclaimed samples. The results indicate that no significant difference exists between the samples $(p>0.05)$; that is to say, the effect of samples on the inner validity of research results is negligible.

First of all, this paper makes descriptive statistics of the 245 valid questionnaires on the perspective of members, including gender, age, education, planting years, and accessing to cooperatives years, and the result is as shown in Table 1. Overall, the obtained samples can satisfy the research requirements of this paper.

3.1.2. Variable Measurement. In the measurement of all variables, this paper asks the members about their personal perception using the Likert five-scale forms, and "1" represents "totally disagree," "3" represents "not sure," "5" represents "completely agree," and " 2 " and "4" represent "between the situation." The greater the number is, the more positive the member's view is. The variables used in this study are derived from existing literature and are adjusted accordingly to the context of the study.

(1) Interactive Justice (IJ). This paper measures the interactive justice variables based on previous scholars [16, 28]; using the problems of "the capable person can treat me in good manners, the capable person can take my dignity into consideration and respect me; the capable person can consider my needs when making decisions" and other problems to measure interpersonal justice perception (IPJP) of the members; the capable person can take the initiative to communicate with members and seek advice of them; the capable person can open to the members for useful information, and the capable person explains in detail the relevant decision and other problems to represent the members' informational justice perception (IJP).

(2) Relational Embeddedness (RE). Based on the measure method of relational embeddedness variable of Uzzi [30], Evily, and Marcus [32], this paper uses the members and capable person interaction and contact frequently, the members and capable person can keep promise, and the members and capable person put a lot of faith in each other; they will not use each other's weakness for personal benefit' to measure the trust degree between them, this paper measures the informational sharing (IS) variable with 
TABLE 1: Descriptive statistics of sample data.

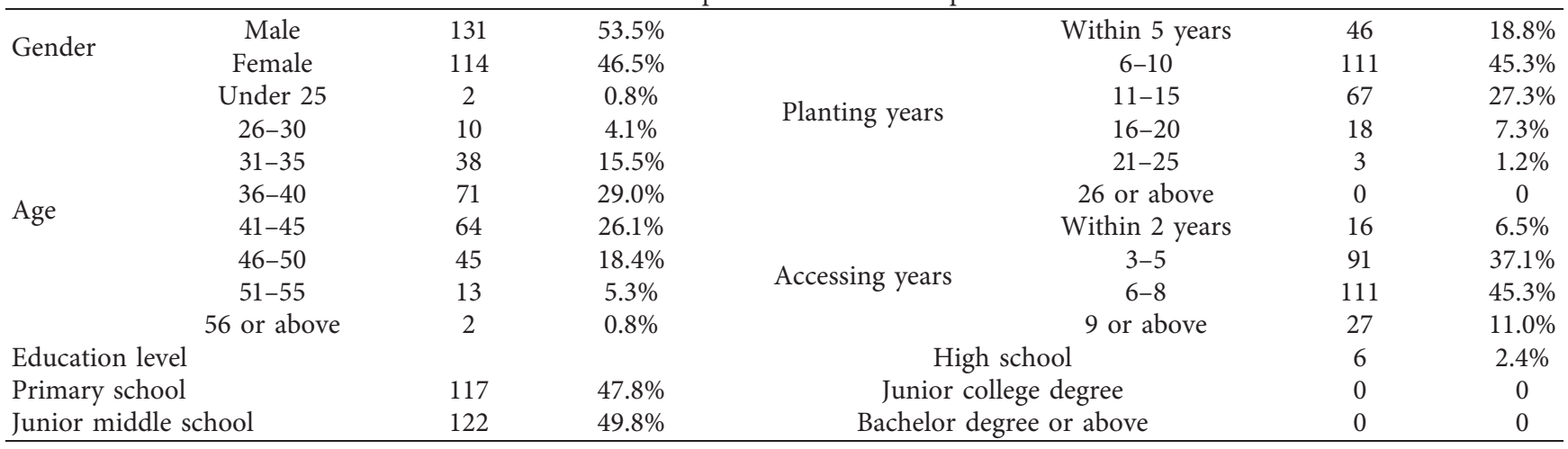

problems such as the members and capable person are willing to exchange information, the members and capable exchange information are not confined to the protocol, the members and capable person can remind each other their present problems, and the capable person is capable of sharing the future development plan of the agricultural cooperatives with the members; this paper uses the fact that the members and capable person can help each other to solve problems, the members and capable person can share the responsibility, the members and capable person can work together to overcome the difficulties in the process of agricultural cooperatives' operation, and the members and capable person can work together to accomplish the task of producing certain agricultural products and other problems to measure collectively solving problem (CSP) variable.

(3) Relational Governance Performance (RGP). Based on the research results of relational governance performance variable from previous scholars [29, 30], this paper uses problems such as "the satisfaction of members on agricultural cooperatives" governance, the participation of members in the agricultural cooperatives daily affairs, the proportion of income increasing, and other problems to measure the relational governance performance (RGP) level.

(4) Control Variables. In this paper, based on existing research results, the control variables are set for the age (Age), planting years (PY), accessing years (AY), and education level (EL) of the members, and then this paper tests the influence of the independent variable (interactive justice) and intermediary variable (relational embeddedness) on the dependent variable (relational governance performance).

3.2. Fuzzy Cognitive Map. In this paper, the influence relationship among variables cannot be ignored, and this relationship is not only a linear relationship solved by regression but also a more nonlinear relationship. Deep learning can solve the nonlinear problem very well. Therefore, we introduce machine learning, combined with fuzzy cognitive map to train the problem variables.

In 1986, Kosko et al. put forward the theory of fuzzy cognitive map (FCM) based on cognitive map and fuzzy set theory. Fuzzy cognitive map has strong knowledge representation and causal reasoning ability and has good explanatory ability. It has been applied in strategic planning, policy analysis, and other fields.

The fuzzy cognitive map is a kind of fuzzy reasoning calculation tool which combines fuzzy set theory and cognitive map [48]. The fuzzy set theory is based on the fuzzy set, and its basic spirit is to accept the fact that fuzzy phenomenon exists. It aims at dealing with vague and uncertain concepts and actively quantifies them into information that can be processed by computer. Cognitive map is a graph theory tool used to describe the relationship between concepts in complex systems. Based on the theory of fuzzy set, fuzzy cognitive map transforms fuzzy causality into computable numerical model, and its circular feedback mechanism is especially suitable for the relationship reasoning calculation in dynamic system. The fuzzy cognitive map is composed of nodes and arcs, which can be concepts and entities. The arcs represent the causal relationship between concepts or entities [49]. In structure, they can be regarded as object-oriented single-layer neural network with feedback. It supports the representation and reasoning of expert prior knowledge and causality. The knowledge is contained in the relationship between concept nodes, and the system dynamic behavior is simulated by the interaction of each concept node in the whole diagram.

In addition, fuzzy cognitive map is a dynamic system modeling method based on causal reasoning. Fuzzy cognitive map is a combination of fuzzy logic and machine learning method. It has intuitive expression ability and powerful reasoning ability. Therefore, this method can be used to construct the performance model of relational governance under the influence of interactive justice, and the correlation between variables can be expressed by directed loop graph. Directed loop graph consists of nodes and directed edges, in which nodes are divided into input nodes and output nodes. The corresponding concept of output node is a concept that has a reference value for the final result. The influence relationship between nodes is expressed by the connection weights on the edges.

In this paper, we will use the fuzzy cognitive map to construct the relational governance performance model. The input of the model is independent variable, intermediate variable, and control variable, and the weight of the fuzzy cognitive map is optimized by the genetic algorithm. 
3.3. Establishment of Relational Governance Performance Model Based on Fuzzy Cognitive Map. In this paper, we use the fuzzy cognitive map to build a model for this problem. The model consists of ten nodes, namely, control variables-age of members $\mathrm{C} 1$, planting years $\mathrm{C} 2$, time of joining agricultural cooperatives $\mathrm{C} 3$, education level $\mathrm{C} 4$, independent variable interpersonal justice $\mathrm{C} 5$, information justice C6, intermediary variable trust C7, information share C8, solve together $\mathrm{C} 9$, and dependent variable relational governance performance C10.

By selecting real-coded genetic algorithm (RCGA) to train the statistical data of the above ten concept nodes, the weight matrix $\mathrm{W}$ of the relationship between concepts is obtained in this paper. If the relationship between concept and concept is positive, then the increase in concept value will lead to the increase in concept value. Similarly, if the relationship between concept and concept is negative, when there is no relationship between the two concepts, then the increase in concept value will lead to the increase in concept value. Ten indicators are used as conceptual nodes. When connecting nodes, we think that the relationship between nodes affects each other. A line with an arrow indicates the influence of one node on another, and the relationships among nodes are used as directed links to form a fuzzy cognitive map, as shown in Figure 2.

In the measurements of all variables, members are asked about their personal identity or perception in the form of Likert scale 5. Number 1 is used to express "total disagreement," number 3 is used to express "uncertainty," number 5 is used to express "total agreement," and numbers 2 and 4 are in the middle. The larger the number is, the more obvious the positive views of members is. Variables used in this study are derived from existing literatures, and these variables are adjusted according to the research situation. Before training, in this paper, the data are treated as dimensionless data and the original data are compressed to between 0 and 1 ; then, the genetic algorithm is used to optimize the weight matrix. The learning process includes three steps such as selection, crossover, and mutation. Individuals with low fitness will be eliminated gradually, while there will be more and more individuals with high fitness. After natural selection for many generations, individuals with high fitness will be preserved. The training process is as follows:

(1) Coding: the model includes 10 indicators corresponding to 100 weights, and the range of values is $[-1,1]$. The 100 weights are coded in real numbers, $W=\left\{w_{1,1}, w_{1,2}, w_{1,3} \cdots w_{10,10}\right\}$, in which $\mathrm{W}$ is called the chromosome in genetic algorithm.

(2) Initial population: the initial population size is 150. The initial population size is how many chromosomes are currently involved in training, and it is only a parameter of genetic algorithm. It has nothing to do with the questionnaire data, so we set it to 150 . Of course, we can also set it to other numbers.

(3) Fitness calculation: calculate the fitness of each chromosome in the population.

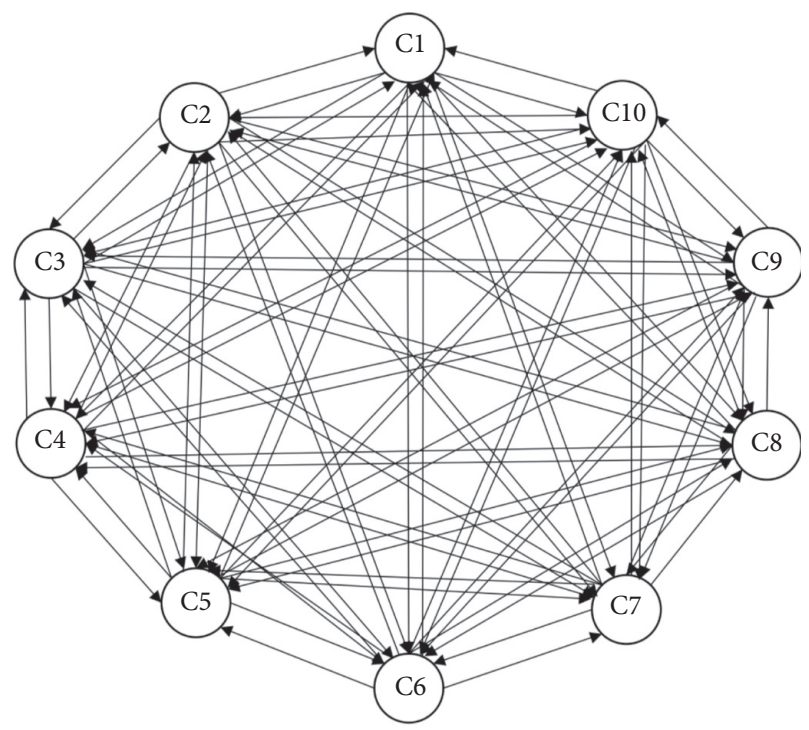

FIgUre 2: Fuzzy cognitive map.

(4) Choosing: the elite choosing method is used to select chromosomes.

(5) Crossing: select single-point crossing and randomly select each crossing point. The crossover point is a data position in chromosome $\mathrm{W}$, and the crossover rate parameter $\mathrm{Pc}$ is set.

(6) Variation: choosing a chromosome location randomly according to the mutation step to modify the location data and set the mutation rate parameter Mt.

Through the above steps, the optimal weight matrix $W$ is obtained as follows:

$$
W=\left[\begin{array}{cccccccccc}
0 & 0 & 0.2 & 0.18 & 0.59 & 0.82 & 0.76 & 0.27 & 0.3 & 0 \\
0 & 0 & 0 & 0 & 0 & 0.67 & 0.57 & 0 & 0 & 0 \\
0 & 0 & 0 & 0 & 0.33 & 0.64 & 0.32 & 0 & 0.7 & -0.18 \\
0 & 0 & 0 & 0 & 0 & 0.2 & 0 & 0 & 0.8 & 0 \\
0 & 0 & 0 & 0 & 0 & 0.5 & 0.7 & 0 & 0.5 & 0.55 \\
0.44 & 0.2 & 0.4 & 0 & 0 & 0 & 0.4 & 0 & 0 & 0.42 \\
0 & 0 & 0.36 & 0 & 0.37 & 0.8 & 0 & -0.45 & 0.57 & 0.67 \\
0 & 0 & 0.2 & 0 & 0.59 & -0.72 & 0.5 & 0 & 0 & 0.74 \\
-0.24 & -0.33 & 0.2 & 0 & 0.77 & 0.95 & 0 & 0 & 0 & 0.85 \\
0 & 0 & 0 & 0 & 0.2 & 0.15 & 0 & 0.23 & 0.34 & 0
\end{array}\right] .
$$

Thus, we construct a model of interactive justice, relational embeddedness, and governance performance, as shown in Figure 3.

3.4. Model to Be Tested. Based on the theoretical hypothesis of this paper, the regression models to be tested are as follows: 


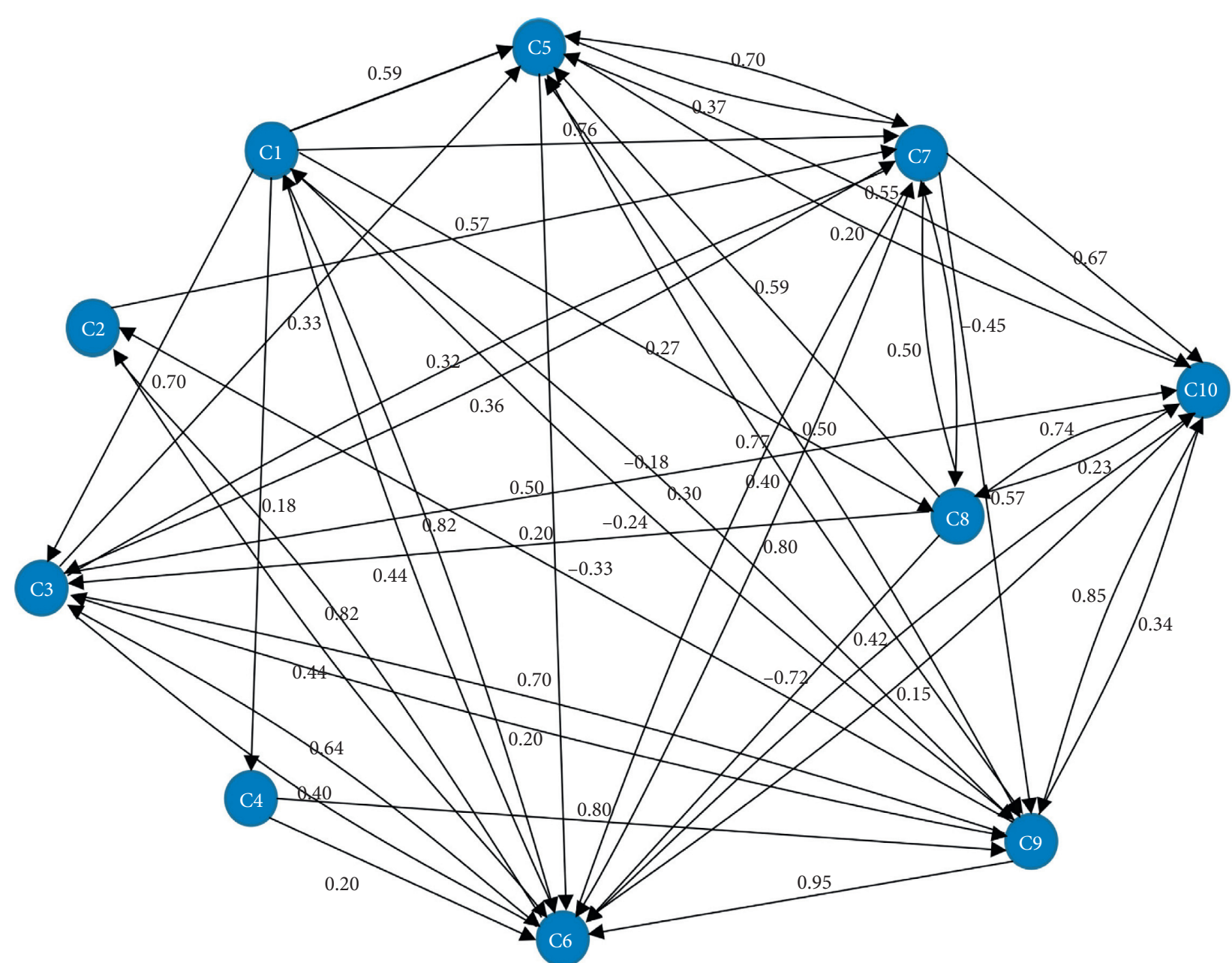

Figure 3: Interactive justice, relational embeddedness, and governance performance model.

$$
\begin{aligned}
& \mathrm{RGP}=\alpha+\beta_{1} X+\varepsilon, \\
& \mathrm{RGP}=\alpha+\beta_{1} X+\beta_{2} \mathrm{IPJP}+\varepsilon, \\
& \mathrm{RGP}=\alpha+\beta_{1} X+\beta_{2} \mathrm{IJP}+\varepsilon, \\
& \mathrm{RGP}=\alpha+\beta_{1} X+\beta_{2} \mathrm{IS}+\varepsilon, \\
& \mathrm{RGP}=\alpha+\beta_{1} X+\beta_{2} \mathrm{IS}+\varepsilon, \\
& \mathrm{RGP}=\alpha+\beta_{1} X+\beta_{2} \mathrm{CSP}+\varepsilon, \\
& \mathrm{RGP}=\alpha+\beta_{1} X+\beta_{2} \mathrm{Trust}^{2}+\varepsilon, \\
& \mathrm{RGP}=\alpha+\beta_{1} X+\beta_{2} \mathrm{IS}^{2}+\varepsilon, \\
& \mathrm{RGP}=\alpha+\beta_{1} X+\beta_{2} \mathrm{CSP}^{2}+\varepsilon, \\
& \mathrm{RGP}=\alpha+\beta_{1} X+\beta_{2} \mathrm{IPJP}^{2} \beta_{3} \text { Trust }+\varepsilon, \\
& \mathrm{RGP}=\alpha+\beta_{1} X+\beta_{2} \mathrm{IJP}+\beta_{3} \text { Trust }+\varepsilon,
\end{aligned}
$$

$$
\begin{aligned}
\mathrm{RGP} & =\alpha+\beta_{1} X+\beta_{2} \mathrm{IPJP}+\beta_{3} \mathrm{IS}+\varepsilon, \\
\mathrm{RGP} & =\alpha+\beta_{1} X+\beta_{2} \mathrm{IJP}+\beta_{3} \mathrm{IS}+\varepsilon, \\
\mathrm{RGP} & =\alpha+\beta_{1} X+\beta_{2} \mathrm{IPJP}+\beta_{3} \mathrm{CSP}+\varepsilon, \\
\mathrm{RGP} & =\alpha+\beta_{1} X+\beta_{2} \mathrm{IJP}+\beta_{3} \mathrm{CSP}+\varepsilon, \\
\text { Trust } & =\alpha+\beta_{1} X+\beta_{2} \mathrm{IPJP}+\varepsilon \\
\mathrm{IS} & =\alpha+\beta_{1} X+\beta_{2} \mathrm{IPJP}+\varepsilon \\
\mathrm{CSP} & =\alpha+\beta_{1} X+\beta_{2} \mathrm{IPJP}+\varepsilon \\
\text { Trust } & =\alpha+\beta_{1} X+\beta_{2} \mathrm{IJP}+\varepsilon, \\
\mathrm{IS} & =\alpha+\beta_{1} X+\beta_{2} \mathrm{IJP}+\varepsilon, \\
\mathrm{CSP} & =\alpha+\beta_{1} X+\beta_{2} \mathrm{IJP}+\varepsilon .
\end{aligned}
$$

The RGP is an explained variable, and it represents relational governance performance; the IPJP and IJP are 
explanatory variables, and they represent interpersonal justice perception and informational justice perception; the trust, IS, and CSP are intermediary variables, and they, respectively, represent trust, information sharing, and collaboratively solving problems; $X$ indicates control variable, and $\varepsilon$ represents random disturbance term. Model (2) are used to test the impact of control variables on the dependent variable; the model (3) and model (4) examined the direct effect of independent variables on the dependent variable; the model (5)-model (10) are used to test the inverted " $U$ " relations between the intermediary variables and the dependent variable; the model (11)-model (16) are mainly used to test the mediating effect; and the model (17)-model (22) examine the direct effect of independent variables on the intermediary variables. Thus, the relationship between the governance performance and the influencing factors is as follows:

$$
\begin{aligned}
\mathrm{RGP}= & \beta_{0}+\beta_{1} \mathrm{IPJP}+\beta_{2} \mathrm{IJP}+\beta_{3} \text { Trust }+\beta_{4} \mathrm{IS}+\beta_{5} \mathrm{CSP} \\
& +\beta_{6} \text { Trust }^{2}+\beta_{7} \mathrm{IS}^{2}+\beta_{8} \mathrm{CSP}^{2}+\beta_{9} \mathrm{Age}+\beta_{10} \mathrm{PY} \\
& +\beta_{11} \mathrm{AY}+\beta_{12} \mathrm{EL}+\varepsilon .
\end{aligned}
$$

\section{Empirical Test}

4.1. Correlation Analysis. Firstly, this paper carries out the correlation analysis before the regression analysis. The relationship between the age, planting years, accessing to agricultural cooperatives years, education level of the members, and the governance performance is not significant, but there are strong correlations between the interpersonal justice perception $(\beta=0.607, \quad p<0.01)$, informational justice perception $(\beta=0.731, p<0.01)$, trust $(\beta=0.843, \quad p<0.01)$, information sharing $(\beta=0.908$, $p<0.01)$, collaboratively solving problems $(\beta=0.933$, $p<0.01$ ), and the governance performance. From Table 2, the minimum value of AVE is 0.673 and it is greater than 0.5 , which indicates that the distinctive validity is ideal. In addition, the minimum value of the combination reliability is 0.892 and it is greater than 0.6 , which shows that the internal correlation between the measurement index of the same variable is more satisfactory and acceptable.

4.2. Reliability and Validity Test. Before testing the relevant hypotheses, this paper carries out the validity and reliability analysis of each variable. From the exploratory factor analysis results of Table 3, it shows that the minimum Cronbach's $\alpha$ value of all the variables is 0.834 and it is much higher than the minimum standard value 0.70 , and the factor loading coefficients reaches more than the minimum standard value 0.5 , which represents that each variable has good internal consistency and reliability; that is to say, the results can meet the needs of this study. In addition, the minimum KMO value is 0.717 . It is more than the minimum standard value 0.7 and reaches the significant level $(p<0.001)$, which shows that the scales do have common factors and the sample data collected are available for factor analysis; that is to say, the variables' effective degree is high.

\subsection{Empirical Analysis and Results}

4.3.1. Direct Effect Test. As shown in Table 4, the model 2 adds the interpersonal fairness variable on the basis of model 1 and the explanation of interpersonal fairness on the governance performance increases by $37.4 \%$, which shows that the interpersonal fairness plays an important role in the interpretation of the governance performance $\left(R^{2}=0.379\right)$. The interpersonal justice has a significant positive effect on governance performance $(\beta=0.614, p<0.01)$. Similarly, the model 3 adds the informational fairness on the basis of model 1, and the regression result shows that the informational fairness also has a significant positive effect on relational governance performance $(\beta=0.734, p<0.01)$. To sum up, there is a significant positive correlation between interactive justice and relational governance performance. Therefore, hypothesis such as H1, H1a, and H1b can be verified.

The model 4 , based on the model 1 , adds intermediary variable trust, and the regression result shows that the trust has a significant positive effect on relational governance performance $(\beta=0.713, p<0.01)$. The model 5 on the basis of the model 4 adds the square of trust and the regression coefficient becomes from positive to negative $(\beta=-0.226$, $p<0.01)$, which means that there is an significant inverted "U" relationship between the trust and relational governance performance. Therefore, the hypothesis $\mathrm{H} 2 \mathrm{a}$ is verified. Similarly, the model 6 adds mediation variable information sharing on the basis of the model 1 , and the regression result shows that the information sharing has a significant positive impact on relational governance performance $(\beta=0.908$, $p<0.01$ ). The model 7 on the basis of the model 6 adds the square of information sharing, and the regression coefficient becomes from positive to negative $(\beta=-0.257, p<0.01)$, which means that there is an significant inverted " $U$ " relationship between the information sharing and relational governance performance. Therefore, the hypothesis $\mathrm{H} 2 \mathrm{~b}$ is verified. The model 8 , based on the model 1 , adds intermediary variable collaboratively solving problems, and the regression result shows that collaboratively solving problems has a significant positive effect on relational governance performance $(\beta=0.934, p<0.01)$. The model 9 on the basis of the model 8 adds the square of collaboratively solving problems, and the regression coefficient becomes from positive to negative $(\beta=-0.232, p<0.01)$, which means that there is an significant inverted " $U$ " relationship between the collaboratively solving problems and relational governance performance. Therefore, the hypothesis $\mathrm{H} 2 \mathrm{c}$ is verified. In summary, the $\mathrm{H} 2$ all passes the test and there is an inverted " $U$ " relationship between relational embeddedness and governance performance; that is to say, the moderate relational embeddedness is conducive to enhance the level of performance and the excessive relational embeddedness has a negative impact on the governance performance.

4.3.2. Mediating Effect Test. From Table 5, it can be found that the model 2 adds the interpersonal fairness on the basis of model 1 and the explanation of the trust increases 51.7\% 
TABLE 2: Correlation analysis of variables.

\begin{tabular}{|c|c|c|c|c|c|c|c|c|c|c|}
\hline Variable name & 1 & 2 & 3 & 4 & 5 & 6 & 7 & 8 & 9 & 10 \\
\hline Age & 1 & & & & & & & & & \\
\hline Planting years & $0.707^{* * *}$ & 1 & & & & & & & & \\
\hline Accessing years & $0.560^{* * *}$ & $0.552^{* * *}$ & 1 & & & & & & & \\
\hline Education level & $-0.346^{* * *}$ & $-0.211^{* * *}$ & -0.105 & 1 & & & & & & \\
\hline Interpersonal justice & -0.037 & -0.080 & -0.009 & 0.040 & 1 & & & & & \\
\hline Informational justice & 0.013 & -0.024 & -0.001 & 0.011 & $0.840^{* * *}$ & 1 & & & & \\
\hline Trust & -0.053 & -0035 & -0.035 & 0.020 & $0.718^{* * *}$ & $0.881^{* * *}$ & 1 & & & \\
\hline Information sharing & -0.030 & 0.022 & -0.028 & 0.047 & $0.548^{* * *}$ & $0.721^{* * *}$ & $0.866^{* * *}$ & 1 & & \\
\hline Collaboratively solving problems & -0.061 & -0.004 & -0.051 & 0.040 & $0.622^{* * *}$ & $0.730^{* * *}$ & $0.860^{* * *}$ & $0.943^{* * *}$ & 1 & \\
\hline Governance performance & -0.048 & -0.013 & -0.050 & 0.042 & $0.607^{* * *}$ & $0.731^{* * *}$ & $0.843^{* * *}$ & $0.908^{* * *}$ & $0.933^{* * *}$ & 1 \\
\hline Mean & 4.559 & 2.269 & 2.620 & 1.547 & 3.151 & 3.509 & 3.579 & 3.638 & 3.560 & 3.603 \\
\hline $\mathrm{SD}$ & 1.300 & 0.892 & 0.799 & 0.546 & 1.132 & 0.702 & 0.947 & 1.009 & 1.068 & 1.162 \\
\hline Average & - & - & - & - & 0.862 & 0.673 & 0.778 & 0.833 & 0.852 & 0.870 \\
\hline Combination reliability & - & - & - & - & 0.949 & 0.892 & 0.933 & 0.952 & 0.958 & 0.964 \\
\hline
\end{tabular}

Notes. ${ }^{* * *}$ Significant correlations at the 0.01 level (bilateral).

TABLE 3: Reliability and validity of each variable.

\begin{tabular}{|c|c|c|c|}
\hline Variables & Measurement item & $\begin{array}{c}\text { Cronbach's } \\
\alpha\end{array}$ & $\mathrm{KMO}$ \\
\hline Interpersonal justice & $\begin{array}{l}\text { (1) The capable person can treat me in good manners }(0.935) \\
\text { (2) The capable person can take my dignity into consideration and respect me }(0.942) \\
\text { (3) The capable person can consider my needs when making decisions }(0.908)\end{array}$ & 0.916 & 0.749 \\
\hline Informational justice & $\begin{array}{l}\text { (1) The capable person can take the initiative to communicate with members and seek } \\
\text { advice of them }(0.831) \\
\text { (2) The capable person can open to the members for useful information }(0.837) \\
\text { (3) The capable person explains in detail the relevant decision }(0.802) \\
\text { (4) The capable person is able to interpret relevant decisions or questions more } \\
\text { rationally }(0.811)\end{array}$ & 0.834 & 0.811 \\
\hline Trust & $\begin{array}{l}\text { (1) The members and capable person interact and contact frequently }(0.847) \\
\text { (2) The members and capable person can keep promise }(0.941) \\
\text { (3) The members and capable person put a lot of faith in each other }(0.906) \\
\text { (4) You will not use each other's weakness for personal benefit }(0.830)\end{array}$ & 0.905 & 0.796 \\
\hline Information sharing & $\begin{array}{l}\text { (1) The members and capable person are willing to exchange information }(0.876) \\
\text { (2) The members and capable exchange information are not confined to the protocol } \\
(0.942) \\
\text { (3) The members and capable can remind each other his present problems }(0.901) \\
\text { (4) The capable person is capable of sharing the future development plan of the } \\
\text { agricultural cooperatives with the members }(0.931)\end{array}$ & 0.929 & 0.839 \\
\hline $\begin{array}{l}\text { Collaboratively solving } \\
\text { problems }\end{array}$ & $\begin{array}{l}\text { (1) The members and capable person can help each other to solve problems }(0.912) \\
\text { (2) The members and capable person can share the responsibility }(0.954) \\
\text { (3) The members and capable person can work together to overcome the difficulties in } \\
\text { the process of agricultural cooperatives' operation }(0.912) \\
\text { (4) The members and capable person can work together to accomplish the task of } \\
\text { producing certain agricultural products }(0.914)\end{array}$ & 0.938 & 0.717 \\
\hline Governance performance & $\begin{array}{l}\text { (1) Your satisfaction of members on agricultural cooperatives' governance }(0.945) \\
\text { (2) Your participation of members in the agricultural cooperatives daily affairs }(0.962) \\
\text { (3) Your proportion of income increasing }(0.879) \\
\text { (4) Do you think the relationship and benefits distribution between the members is } \\
\text { clear? }(0.943)\end{array}$ & 0.947 & 0.774 \\
\hline
\end{tabular}

compared with the control variables, which means the interpersonal justice has a significant positive impact on trust $(\beta=0.723, p<0.01)$. Similarly, the model 5 adds the interpersonal fairness on the basis of model 4 and the explanation of the information sharing increases $30.7 \%$ compared with the control variables, which means the interpersonal justice has a significant positive impact on information sharing $(\beta=0.556, p<0.01)$. The model 8 adds the interpersonal justice on the basis of model 7 , and the regression result shows that there is a significant positive correlation between interpersonal justice and collaboratively solving problems $(\beta=0.631, p<0.01)$. In summary, the trust, information 
TABLE 4: Regression analysis results of interactive justice and relational embeddedness on governance performance.

\begin{tabular}{|c|c|c|c|c|c|c|c|c|c|}
\hline & \multicolumn{9}{|c|}{ Relational governance performance } \\
\hline & Model 1 & Model 2 & Model 3 & Model 4 & Model 5 & Model 6 & Model 7 & Model 8 & Model 9 \\
\hline \multicolumn{10}{|c|}{ Control variables } \\
\hline Age & -0.049 & -0.072 & -0.099 & -0.004 & 0.014 & 0.006 & 0.011 & 0.035 & 0.059 \\
\hline PY & 0.056 & 0.131 & 0.106 & 0.049 & 0.035 & -0.033 & -0.021 & -0.029 & -0.045 \\
\hline AY & -0.051 & -0.076 & -0.051 & -0.043 & -0.054 & -0.011 & -0.025 & -0.005 & -0.017 \\
\hline EL & 0.031 & 0.012 & 0.016 & 0.030 & 0.033 & -0.007 & -0.006 & 0.010 & 0.013 \\
\hline \multicolumn{10}{|c|}{ Independent variables } \\
\hline IPJP & & $0.614^{* * *}$ & & & & & & & \\
\hline IJP & & & $0.734^{* * *}$ & & & & & & \\
\hline \multicolumn{10}{|c|}{ Mediator variables } \\
\hline Trust & & & & $0.842^{* * *}$ & $0.678^{* * *}$ & & & & \\
\hline Trust $^{2}$ & & & & & $-0.226^{* * *}$ & & & & \\
\hline IS & & & & & & $0.908^{* * *}$ & $0.716^{* * *}$ & & \\
\hline IS $^{2}$ & & & & & & & $-0.257^{* * *}$ & & \\
\hline CSP & & & & & & & & $0.934^{* * *}$ & $0.757^{* * *}$ \\
\hline $\mathrm{CSP}^{2}$ & & & & & & & & & $-0.232^{* * *}$ \\
\hline$R^{2}$ & 0.005 & 0.379 & 0.543 & 0.713 & 0.736 & 0.825 & 0.854 & 0.870 & 0.892 \\
\hline Adjusted $R^{2}$ & -0.011 & 0.366 & 0.534 & 0.707 & 0.730 & 0.821 & 0.851 & 0.868 & 0.890 \\
\hline$\Delta R^{2}$ & 0 & 0.374 & 0.538 & 0.708 & 0.017 & 0.82 & 0.026 & 0.865 & 0.02 \\
\hline VIFmax & & & & & $2.443<3$ & & & & \\
\hline
\end{tabular}

Notes. ${ }^{* * *}$ Significant correlations at the 0.01 level (bilateral).

TABle 5: Regression analysis of the influence of interactive fairness on relational embeddedness.

\begin{tabular}{|c|c|c|c|c|c|c|c|c|c|}
\hline & \multicolumn{3}{|c|}{ Trust } & \multicolumn{3}{|c|}{ Information sharing } & \multicolumn{3}{|c|}{ Collaboratively solving problems } \\
\hline & Model 1 & Model 2 & Model 3 & Model 4 & Model 5 & Model 6 & Model 7 & Model 8 & Model 9 \\
\hline \multicolumn{10}{|c|}{ Control variable } \\
\hline Age & -0.053 & -0.080 & $-0.114^{* *}$ & -0.060 & -0.081 & -0.110 & -0.089 & -0.113 & $-0.139^{* *}$ \\
\hline PY & 0.009 & 0.096 & 0.068 & 0.098 & $0.166^{* *}$ & $0.147^{* *}$ & 0.091 & $0.168^{* *}$ & $0.141^{* *}$ \\
\hline AY & -0.010 & -0.039 & -0.010 & -0.044 & -0.066 & -0.044 & -0.049 & -0.075 & -0.049 \\
\hline $\mathrm{EL}$ & 0.002 & -0.021 & -0.016 & 0.042 & 0.024 & 0.027 & 0.023 & 0.003 & 0.008 \\
\hline \multicolumn{10}{|c|}{ Independent variables } \\
\hline IPJP & & $0.723^{* * *}$ & & & $0.556^{* * *}$ & & & $0.631^{* * *}$ & \\
\hline IJP & & & $0.885^{* * *}$ & & & $0.725^{* * *}$ & & & $0.735^{* * *}$ \\
\hline$R^{2}$ & 0.003 & 0.520 & 0.783 & 0.007 & 0.314 & 0.532 & 0.008 & 0.403 & 0.547 \\
\hline Adjusted $R^{2}$ & -0.014 & 0.510 & 0.779 & -0.009 & 0.299 & 0.522 & -0.008 & 0.390 & 0.538 \\
\hline$\Delta R^{2}$ & 0 & 0.517 & 0.78 & 0 & 0.307 & 0.525 & 0 & 0.395 & 0.539 \\
\hline VIFmax & & & & & $2.404<3$ & & & & \\
\hline
\end{tabular}

Notes. ${ }^{* *}$ Significant correlations at the 0.05 level (bilateral); ${ }^{* * *}$ significant correlations at the 0.01 level (bilateral).

sharing, and collaboratively solving problems all have significant positive effects on the relational embeddedness; that is to say, there is a significant positive correlation between interpersonal justice and relational embeddedness. The higher the level of interpersonal justice perceived by the members is, the higher the relational embeddedness degree is in agricultural cooperatives.

The model 3, model 6 , and model 9 add the informational justice, respectively, the basis of the model 1 , model 4 , and model 7 . The regression results show that the informational justice has a significant positive effect on the trust $(\beta=0.885, \quad p<0.01)$, information sharing $(\beta=0.725$, $p<0.01)$, and collaboratively solving problems $(\beta=0.735$, $p<0.01)$; that is to say, there is a significant positive correlation between informational justice and relational embeddedness. The higher the level of informational justice perceived by the members is, the higher the relational embeddedness degree is in agricultural cooperatives. In conclusion, there is a significant positive correlation between interactive justice and relational embeddedness.

From Table 6 , the model 3 adds the mediating variable trust on the basis of model 2 and the regression result shows that the influence coefficient of interpersonal justice on relational governance performance is not significant $(\beta=0.011, p>0.1)$, but the trust has a significant positive effect on governance performance $(\beta=0.834, p<0.01)$. Therefore, the trust plays a mediating role completely in the relationship between the interpersonal justice and governance performance. The model 3 adds the mediating variable information sharing on the basis of model 2, and the influence of interpersonal justice on relational governance performance coefficient decreases according to the 
TABLE 6: Regression analysis results of mediating effects of relational embeddedness.

\begin{tabular}{|c|c|c|c|c|c|c|c|c|c|}
\hline & \multicolumn{9}{|c|}{ Relational governance performance } \\
\hline & Model 1 & Model 2 & Model 3 & Model 4 & Model 5 & Model 6 & Model 7 & Model 8 & Model 9 \\
\hline \multicolumn{10}{|c|}{ e } \\
\hline Age & -0.049 & -0.072 & -0.005 & -0.005 & 0.031 & -0.099 & 0.001 & -0.012 & 0.020 \\
\hline $\mathrm{PY}$ & 0.056 & 0.131 & 0.050 & -0.005 & -0.021 & 0.106 & 0.045 & -0.011 & -0.015 \\
\hline $\mathrm{AY}$ & -0.051 & -0.076 & -0.043 & -0.021 & -0.008 & -0.051 & -0.042 & -0.016 & -0.009 \\
\hline EL & 0.031 & 0.012 & 0.029 & -0.008 & 0.009 & 0.016 & 0.030 & -0.005 & 0.009 \\
\hline \multicolumn{10}{|l|}{ Independent variables } \\
\hline IPJP & & $0.614^{* * *}$ & 0.011 & $0.157^{* * *}$ & 0.041 & & & & \\
\hline $\mathrm{IJP}$ & & & & & & $0.734^{* * *}$ & -0.048 & $0.160^{* * *}$ & $0.105^{* *}$ \\
\hline \multicolumn{10}{|l|}{ Mediator variables } \\
\hline Trust & & & $0.834^{* * *}$ & & & & $0.885^{* * *}$ & & \\
\hline Information sharing & & & & $0.821^{* * *}$ & & & & $0.792^{* * *}$ & \\
\hline Collaboratively solving problems & & & & & $0.908^{* * *}$ & & & & $0.856^{* * *}$ \\
\hline$R^{2}$ & 0.005 & 0.379 & 0.713 & 0.842 & 0.871 & 0.543 & 0.713 & 0.837 & 0.875 \\
\hline Adjusted $R^{2}$ & -0.011 & 0.366 & 0.705 & 0.838 & 0.868 & 0.534 & 0.706 & 0.833 & 0.872 \\
\hline$\Delta R^{2}$ & 0 & 0.374 & 0.326 & 0.459 & 0.489 & 0.538 & 0.163 & 0.29 & 0.329 \\
\hline VIFmax & & & & & $4.616<5$ & & & & \\
\hline
\end{tabular}

Notes. ${ }^{* *}$ Significant correlations at the 0.05 level (bilateral); ${ }^{* * *}$ significant correlations at the 0.01 level (bilateral).

regression result $(\beta=0.157<0.614, p<0.01)$, and the information sharing has a significant positive effect on the governance performance $(\beta=0.821, p<0.01)$. As a result, the information sharing plays a partial mediating role in the relationship between the interpersonal justice and governance performance. The model 5 adds the mediating variable collaboratively solving problems on the basis of model 2, and the regression result shows that the influence coefficient of interpersonal justice on relational governance performance is not significant $(\beta=0.041, p>0.1)$, but the collaboratively solving problems has a significant positive effect on governance performance $(\beta=0.908, p<0.01)$. Therefore, the collaboratively solving problems plays a mediating role completely in the relationship between the interpersonal justice and governance performance. To sum up, the hypothesis of H3a is verified. The relational embeddedness has a mediating effect on the relationship between the interpersonal justice and relational governance performance; that is to say, the interpersonal justice influences relational embeddedness and further impacts the governance performance.

Similarly, the model 7 adds the mediating variable trust on the basis of model 6 and the regression results that the influence coefficient of informational justice on relational governance performance is not significant $(\beta=-0.048$, $p>0.01)$, but the trust has a significant positive effect on governance performance $(\beta=0.885, p<0.01)$. Therefore, the trust plays a mediating role completely in the relationship between the informational justice and governance performance. The model 8 adds the mediating variable information sharing on the basis of model 6, the influence coefficient of informational justice on relational governance performance decreases according to the regression result $(\beta=0.160<0.734, p<0.01)$, and the information sharing has a significant positive effect on the governance performance $(\beta=0.792, p<0.01)$. As a result, the information sharing plays a partial mediating role in relationship between the informational justice and governance performance. The model 9 adds the mediating variable collaboratively solving problems on the basis of model 6 , the influence coefficient of informational justice on relational governance performance decreases according to the regression result $(\beta=0.105<0.734, p<0.01)$, and the collaboratively solving problems has a significant positive effect on the governance performance $(\beta=0.856, p<0.01)$.Therefore, the collaboratively solving problems plays a partial mediating role in relationship between the informational justice and governance performance. To sum up, the hypothesis of $\mathrm{H} 3 \mathrm{~b}$ is verified. The relational embeddedness has a mediating effect on the relationship between the informational justice and relational governance performance; that is to say, the informational justice influences relational embeddedness and further impacts the governance performance. Therefore, the hypothesis of $\mathrm{H} 3$ passes the test.

\section{Conclusions and Prospects}

This paper clarifies the internal governance reality of capable person leading agricultural cooperatives and constructs the theoretical model based on the survey data of 18 cooperatives from Shandong Province and constructs a theoretical model of relationship among interactive justice, relational embeddedness, and governance performance based on fuzzy cognitive map, in order to explore the effect of interactive justice between the members and capable person on the governance performance and the mediating effect of the relational embeddedness. The conclusions of this study are as follows.

\subsection{The Interactive Justice Has a Significant Positive Impact on} the Relational Governance Performance of Rural Cooperatives. With the rise of the interpersonal justice and informational justice perceived by the members, the more harmonious the internal relations of agricultural cooperatives is, the more positively the members take part in the internal governance 
of agricultural cooperatives, which will be beneficial to improve the governance performance level. Therefore, in order to further improve the governance performance, the capable person should keep interactive justice with different members in the process of relational governance. On the one hand, based on the different relational governance pattern and balanced relations, the capable person gives relatively fair incentives or support for each member in order to strengthen the fair perception of the members and ultimately makes the governance performance continue to strengthen. On the other hand, the capable person and the cooperatives need to strengthen the equality, openness, and sharing of information so as to improve the service level of cooperatives. Through the continuous introduction of new varieties and technologies to meet the diverse needs of members' cooperation, the members can benefit from it and enhance the level of trust and dependence of the members on the capable person and agricultural cooperatives and ultimately improve the internal cohesion and performance. In addition, the agricultural cooperatives can adopt selective incentive measures in addition to maintaining interactive justice; for example, the agricultural cooperatives give some of the members different or special incentives to improve their enthusiasm to participate in the relational governance of the agricultural cooperatives, so as to effectively enhance the governance level of performance.

\subsection{The Relational Embeddedness Plays an Intermediary Role} between the Interactive Justice and Governance Performance. The interpersonal justice and informational justice can both affect the governance performance through the influence on the trust, information sharing, and collaboratively solving problems. The higher the interactive justice of the members is, the stronger the relational embeddedness between the two sides is, and the higher the agricultural governance performance is. Therefore, in order to improve the enthusiasm of the members to participate in agricultural cooperatives governance, the capable person and cooperatives should take a series of measures to strengthen the trust of their own and reduce the conflicts of interests between the parties through the information sharing and solving problems collaboratively, so as to improve the level of performance. First of all, the capable person should strengthen the closeness of the relationship with the members, inspire the members maintaining moderate strong-reciprocity behaviors, and make the punishment of credible threats to suppress some of the members from the "free rider" behavior, which may be beneficial to reconstruct the agricultural cooperatives, maintain harmonious relationships between the members, and improve the governance performance. In addition, the agricultural cooperatives combine their interests with the members' and construct reasonable earnings allocation mechanism to strengthen the trust, communication, and information sharing between them on the basis of setting the access threshold of the agricultural cooperatives, maintaining an appropriate scale of operation and improving the operation mode, which will ultimately improve the governance performance level of agricultural cooperatives.
This paper also has deficiencies in terms of sample selection; for example, this paper only selects 18 cooperatives from Shandong Province as the representative sample, and different regions may have different research results. So the samples selected in this paper are not random enough, which may influence the universality of the research results. In addition, this paper only considers the effect of interactive justice in organizational justice in the process of the relational governance performance, and the distributive justice and procedural justice are not mentioned as two key variables that affect the governance performance or behaviors of the subjects, which may be the future directions worthy of further being studied. In view of this, the future research can expand the research scope and extend the research time and carry out follow-up survey, in order to obtain the national dynamic sample data and improve the representativeness and universality of the research conclusions. In addition, the future research can comprehensively consider the impact mechanism of the three dimensions of organizational justice on relational governance performance, namely, interactive justice, procedural justice, and distributive justice, or adopt the qualitative comparative analysis method based on the fuzzy set to further investigate the combination path of organizational justice and network embeddedness on the relational governance performance.

\section{Data Availability}

The data used to support the findings of this study are available from the corresponding author upon request. The questionnaire data were acquired mainly through e-mail and paper filling out.

\section{Conflicts of Interest}

The authors declare that they have no conflicts of interest.

\section{Acknowledgments}

This work was supported by the General Projects of the National Social Science Fund (Research on industrial chain synergy mechanism of new type agricultural operators under high quality development target (19BGL150)) and Social Science Youth Project of Shandong Province (Research on the sustainable growth mechanism of farmers professional cooperatives in Shandong Province from the perspective of network embeddedness' (20DGLJ08)).

\section{References}

[1] H. Feng and J. Y. Li, "Evaluation of effect of inter-organizational dependence and relational governance mechanism on performance: regulatory role based on opportunistic behavior," Nankai Business Review, vol. 22, no. 3, pp. 103-111, 2019.

[2] C. P. Yu, C. P. Lin, Z. G. Zhang et al., "Specialized knowledge search, management innovation and firm performance: the moderating effect of cognitive appraisal," Management Word, no. 1, pp. 146-166, 2020. 
[3] Q. Liang, "A review on farmer cooperative literature during 2012-2014," Issues in Agricultural Economy, no. 11, pp. 97$112,2015$.

[4] E. Fischer and M. Qaim, "Linking smallholders to markets: determinants and impacts of farmer collective action in Kenya," World Development, vol. 40, no. 6, pp. 1255-1268, 2012.

[5] D. Wu, Y. Yang, and P. Z. Zhu, "Complementary assets specificity, relational governance and business model design," Science Research Management, vol. 40, no. 3, pp. 104-113, 2019.

[6] U. Awan, A. Kraslawski, and J. Huiskonen, "Buyer-supplier relationship on social sustainability: moderation analysis of cultural intelligence," Cogent Business \& Management, no. 1, p. 1429346, 2018.

[7] U. Awan, "Effects of buyer-supplier relationship on social performance improvement and innovation performance improvement," International Journal of Applied Management Science, vol. 11, no. 1, pp. 21-35, 2019.

[8] Y. L. Ma, "The identification and judgment of the farmer specialized cooperatives in China," China Rural Survey, no. 3 , pp. $65-71,2013$.

[9] S. Z. Huang and H. Y. Fu, "Membership heterogeneity, risk sharing and surplus distribution of farmer professional cooperatives," Issues in Agricultural Economy, no. 8, pp. 57-64, 2014.

[10] D. Xiao, "Performance comparison and promotion strategies of farmers' cooperatives in incomplete contract perspective," Macroeconomics, no. 5, pp. 128-138, 2016.

[11] M. Zhang and Y. J. Han, "Performance evaluation of 'Internet + agriculture' listed companies based on BP neural network," Economic Research Guide, no. 12, pp. 71-75+86, 2019.

[12] B. Wang and D. Q. Guo, "Comprehensive evaluation study of enterprise internal knowledge transfer performance based on BP neural network," Information Science, no. 1, pp. 141-145, 2016.

[13] J. Zhao, "Study on the relationship between enterprise breakthrough innovation factors and innovation performance based on neural network," Science and Technology Management Research, no. 22, pp. 26-33, 2016.

[14] S. Guan, J. H. Wan, and Z. B. Zhong, "Network governance of farmer professional cooperatives-based on the case study of H cooperative," China Rural Survey, no. 5, pp. 31-38, 2015.

[15] W. X. Yu, W. M. Xiong, W. D. Huang et al., "Research on relational governance and its influence on knowledge flow in the innovation network," Studies in Science of Science, no. 2, pp. 373-384, 2020.

[16] R. J. Bies and J. F. Moag, "Interactional justice: communication criteria of fairness," Research on Negotiations in Organizations, JAI Press, Greenwich, CT, USA, 1986.

[17] Q. Q. Zhu and L. R. Long, "Interactive justice: a critical review and its future agenda," Management Review, no. 4, pp. 101106, 2012.

[18] J. Ma and B. Bao, "Research on bullwhip effect in energyefficient air conditioning supply chain," Journal of Cleaner Production, no. 12, pp. 854-865, 2016.

[19] G. E. Lin, Z. G. Chen, and J. A. Zhong, "The preliminary literature review and future research directions of organizational," Justice Psychological Science, no. 4, pp. 1016-1018, 2006.

[20] T. Wang, Q. Q. Zheng, and G. M. Wang, "Why does interactional justice influence organizational citizenship behaviors directed at the organization: the roles of leader proto typicality and organizational identification," Journal of Industrial Engineering Management, vol. 32, no. 4, pp. 71-78, 2018.

[21] M.-E. Olkkonen and J. Lipponen, "Relationships between organizational justice, identification with organization and work unit, and group-related outcomes," Organizational Behavior and Human Decision Processes, vol. 100, no. 2, pp. 202-215, 2006.

[22] W. B. Zhou and X. Z. Ma, "An empirical study of the impact mechanism between organization justice and employee career growth: the mediation effect of perceived organizational support," Economic Management, no. 10, pp. 64-74, 2015.

[23] J. Ma and W. Xie, "Application and research on the complex dynamics behaviour under price-discount promotion policy in inventory control system," International Journal of Logistics Research and Applications, vol. 19, no. 6, pp. 520-536, 2016.

[24] J. Ma and X. Ma, "Measure of the bullwhip effect considering the market competition between two retailers," International Journal of Production Research, vol. 55, no. 2, pp. 313-326, 2017.

[25] Markus, "Do vs Matter: the importance of owners on performance variance in start-up firms," Strategic Management Journal, no. 11, pp. 387-404, 2009.

[26] W. Lou and J. Ma, "Complexity of sales effort and carbon emission reduction effort in a two-parallel household appliance supply chain model," Applied Mathematical Modelling, vol. 64, pp. 398-425, 2018.

[27] X. J. Wang, "Network embeddedness and knowledge sharing among firms," Scientific Decision Making, no. 4, pp. 44-49, 2009.

[28] M. Granovetter, "Economic action and social structure: the problem of embeddedness," American Journal of Sociology, vol. 91, no. 3, pp. 481-510, 1985.

[29] B. Uzzi, "Social structure and competition in interfirm networks: the paradox of embeddedness," Administrative Science Quarterly, vol. 42, no. 1, pp. 35-67, 1997.

[30] M. T. Hansen, "The search-transfer problem: the role of weak ties in sharing knowledge across organization subunits," Administrative Science Quarterly, vol. 44, no. 1, pp. 82-111, 1999.

[31] B. Evily and A. Marcus, "Embedded ties and the acquisition of competitive capabilities," Strategic Management Journal, no. 26, pp. 1033-1055, 2005.

[32] L. T. Hosmer, "Trust: the connecting link between organizational theory and philosophical ethics," Academy of Management Review, no. 20, pp. 379-403, 1995.

[33] J. B. Heide and A. S. Miner, "The shadow of the future: effects of anticipated interaction and frequency of contact on buyerseller cooperation," Academy of Management Journal, no. 35, pp. 265-291, 1992.

[34] R. H. Moorman, "Relationship between organizational justice and organizational citizenship behaviors: do fairness perceptions influence employee citizenship?" Journal of Applied Psychology, vol. 76, no. 6, pp. 845-855, 1991.

[35] L. Wen, "Will farmer cooperatives' governance mechanisms affect their performance? An empirical study of Shandong, Henan and Shaanxi Provinces: based on 153 questionnaires comparative," Economic \& Social Systems, no. 6, pp. 134-144, 2016.

[36] B. Y. Cui, P. Jian, and L. Z. Liu, "The performance decision and paradox of farmers' professional cooperatives: empirical research based on AHP-QR," Journal of Agro-Technical Economics, no. 1, pp. 109-123, 2017.

[37] X. Su, S. S. Zhou, and H. Zhang, “A study on the 'double network' governance of farmers' cooperatives: a comparative 
analysis based on cases," Issues in Agricultural Economy, no. 3, pp. $67-77,2018$.

[38] C. J. Yang, "Relational governance in capable person governing cooperatives: an empirical research on 35 specialized farmers' cooperatives established by capable persons," Journal of Nanjing Agricultural University (Social Sciences Edition), no. 2, pp. 44-53, 2016.

[39] W. Q. Ling, R. Li, J. Nie et al., "Research on the mechanisms of reciprocity for the supervisor-subordinate social exchanges within the Chinese organizational context: a consideration perspective," Management Word, vol. 35, no. 5, pp. 134-148, 2019.

[40] J. Ma and L. Xie, "The comparison and complex analysis on dual-channel supply chain under different channel power structures and uncertain demand," Nonlinear Dynamics, vol. 83, no. 3, pp. 1379-1393, 2016.

[41] J. Ma and H. Ren, "Influence of government regulation on the stability of dual-channel recycling model based on customer expectation," Nonlinear Dynamics, vol. 94, no. 3, pp. 17751790, 2018.

[42] J. Ma, W. Lou, and Y. Tian, "Bullwhip effect and complexity analysis in a multi-channel supply chain considering price game with discount sensitivity," International Journal of Production Research, vol. 57, no. 17, pp. 5432-5452, 2019.

[43] J. Ma and L. Sun, "Complexity analysis about nonlinear mixed Oligopolies game based on production cooperation," IEEE Transactions on Control Systems Technology, vol. 26, no. 4, pp. 1532-1539, 2018.

[44] L. Liu, T. Wang, L. Xie, and X. Zhan, "Influencing factors analysis on land-lost farmers' happiness based on the rough DEMATEL method," Discrete Dynamics in Nature and Society, vol. 2020, Article ID 6439476, 10 pages, 2020.

[45] L. Liu and X. Zhan, "Analysis of financing efficiency of Chinese agricultural listed companies based on machine learning," Complexity, vol. 2019, Article ID 9190273, 11 pages, 2019.

[46] L. Xie, J. Ma, and H. Han, "Implications of stochastic demand and manufacturers' operational mode on retailer's mixed bundling strategy and its complexity analysis," Applied Mathematical Modelling, vol. 55, no. 55, pp. 484-501, 2018.

[47] L. Liu, Y. Zhu, and S. Guo, "The evolutionary game analysis of multiple stakeholders in the low-carbon agricultural innovation diffusion," Complexity, vol. 2020, Article ID 6309545, 12 pages, 2020.

[48] Y. W. Chen, "Research on relation between virtual enterprise resources based on fuzzy cognitive map," Science and Technology Communication, no. 3, pp. 98-100, 2014.

[49] H. Y. Zhang and Z. W. Shi, "Fuzzy cognitive research of the influencing factors during scientific and technological achievements transformation based on innovation diffusion perspective," Science of Science and Management of S.\&T.vol. 34, no. 5, pp. 28-35, 2013.

[50] J. Ma, T. Xu, Y. Hong, and X. Zhang, "Impact research on a nonlinear cold chain evolutionary game under three various contracts," International Journal of Bifurcation and Chaos, vol. 29, no. 5, Article ID 1950058, 2019.

[51] X. Su, H. Liu, and S. Hou, "The trilateral evolutionary game of agri-food quality in farmer-supermarket direct purchase: a simulation approach," Complexity, vol. 2018, no. 2, Article 5185497, 2018. 